\title{
Pengembangan Model Penyebab Rework Pada Pekerjaan Konstruksi Infrastruktur Jalan Dengan Pendekatan Sistem Dinamik
}

\author{
A.A Bagus Oka Khrisna Surya ${ }^{1, *}$, I Putu Artama Wiguna ${ }^{1}$, Erma Suryani $^{2}$ \\ Depatemen Teknik Sipil, ITS, Surabaya ${ }^{1}$, Departemen Sistem Informasi, ITS, Surabaya ${ }^{2}$ \\ Koresponden*, Email: agungoka90@gmail.com
}

\begin{tabular}{ll}
\hline \multicolumn{1}{c}{ Info Artikel } & Abstract \\
\hline Diajukan 27 Juli 2017 & Budget wasting in transportation infrastructure project like road project, is often caused by \\
Diperbaiki 6 Desember 2017 & rework, itsalso affecting the budget, rework also become significant contributor for time wasted \\
Disetujui 7 Desember 2017 & to tardiness of the project. Based on preliminary survey results from 32 road project sites in Bali, \\
& NTB and NTT regions in 2013 and 2014 there were an average of 3 rework events in each \\
& location. This research is intended to develop an optimum scenario to minimalize rework on the \\
road infrastructure project using simulation and modeling. The research variable is formulated & based on the literature study measured with Likert scale. The first model is using Causatic \\
Diagram that will be developed into Stock Flow Diagram with System Dynamic approach. From & the analysis, obtained optimum solution to minimizing the number of rework by conducting \\
Keywords: Road infrastructure & asphalting activities in the dry months with providing training regularly and suitably also \\
project, Rework, System dynamic, & recruiting experienced workers and project supervisor.
\end{tabular}

\begin{abstract}
Abstrak
Pemborosan biaya dalam proyek infrastruktur transportasi seperti proyek jalan sering kali disebabkan oleh timbulnya rework, rework juga menjadi kontributor yang signifikan untuk pemborosan waktu yang menyebabkan keterlambatan. Berdasarkan hasil survei pendahuluan dari 32 lokasi proyek jalan pada wilayah Bali, NTB dan NTT di tahun 2013 dan 2014 diperoleh rata-rata terjadi 3 kejadian rework di tiap lokasinya. Penelitian ini bertujuan untuk mengembangkan model kejadian rework pada proyek infrastruktur jalan khususnya di wilayah Bali, NTB dan NTT. Variabel penelitian dirumuskan berdasarkan hasil studi literatur dengan pengukuran menggunakan skala tingkat persetujuan. Model awal menggunakan bentuk Diagram Kausatik yang kemudian dikembangkan menjadi Stock Flow Diagram dengan simulasi menggunakan pendekatan Sistem Dinamik. Dari hasil analisis dan simulasi pada model diperoleh solusi optimum dalam meminimalisir jumlah rework dengan melakukan kegiatan pengaspalan di bulan-bulan kemarau, memberikan pelatihan dan seminar secara berkala dan berkesesuaian untuk para pekerja serta pengawas dan merekrut pekerja dan pengawas yang bepengalaman.
\end{abstract}

Kata kunci: Proyek infrastruktur jalan, Pekerjaan ulang, Sistem dinamik, Pemodelan

\section{Pendahuluan}

Pemenuhan kebutuhan akan infrastruktur jalan yang memadai dibutuhkan untuk percepatan pertumbuhan ekonomi, sosial dan politik suatu daerah. Salah satu indikator keberhasilan proyek pembangunan infrastruktur jalan dapat diukur dari serapan anggaran dan ketepatan waktu penyelesaian. Dengan jumlah anggaran yang dialokasikan bersifat tetap ditambah lingkup wilayah pembagunan yang besar, maka pemborosan biaya dan keterlambatan tidak boleh terjadi. Pemborosan biaya dalam proyek-proyek infrastruktur transportasi seperti proyek jalan, sering kali disebabkan oleh timbulnya pekerjaan ulang atau rework[1], [2].

Biaya dari rework pada kebanyakan proyek-proyek konstruksi terbilang besar, berkisar pada rentan 5\% hingga $20 \%$ dari nilai kontrak[1]. Selain berdampak pada biaya, rework juga menjadi kontributor yang signifikan terhadap pemborosan waktu dan keterlambatan jadwal dari suatu proyek[3],[4]. Rework rata-rata menambah waktu yang diperlukan untuk penyelesaian proyek sebesar $22 \%$ dari waktu yang direncanakan[2]. Selain itu rework juga telah terindikasi sebagai penyebab kedua untuk hilangnya produktivitas pekerja dan merupakan masalah yang sering timbul baik pada pekerjaan desain maupun konstruksi[5].

Jika mempertimbangkan bahwa dampak buruk yang disebabkan oleh rework cukup banyak maka usaha-usaha untuk menguranginya sangat diperlukan, namun pencapaian tujuan ini tidak akan berhasil dengan baik apabila usaha-usaha tersebut dilakukan secara sporadis tanpa mengetahui sistem aktual didalam kejadian rework tersebut, salah satu cara untuk dapat merepresentasikan suatu sistem agar mudah dipahami dapat dilakukan dengan pemodelan. Selain itu dengan menggunakan model kita tidak perlu takut akan dampak resiko terhadap sistem aktual saat melakukan eksperimen dengan berbagai tujuan tentunya[6]. 
Pada penelitian sebelumnya, Love dkk mengembangkan sebuah model kebijakan procurement dalam rangka mengurangi rework dalam proyek gedung, namun dalam pemodelan tersebut fokus pembuatan model hanya ditujukan untuk mengurangi rework di tahap desain yang mengakibatkan variabel penyebab yang dieksplorasi hanya di fase prakonstruksi, sedangkan Aiyetan dkk juga mengembangkan model rework untuk proyek konstruksi umum dengan menggunakan pendekatan sistem dinamik, kelemahannya model masih bersifat konseptual sehingga dapat dikatakan bahwa bentuk model belum valid[2],[7].

Menurut Forcada, rework pada proyek infrastruktur jalan memiliki dinamika dalam proses terjadinya, maka antar variabel penyebabnya memiliki karakteristik hubungan sebabakibat terhadap suatu besaran yang berubah terhadap waktu, sehingga pada penelitian ini akan mengembangkan model kejadian rework pada proyek jalan dengan pendekatan sistem dinamik dengan ditinjau di tahap berlangsungnya kegiatan konstruksi dimana bentuk modelnya akan divalidasi secara kuantitatif[8].

\section{Metode}

Penelitian ini merupakan penelitian deskriptif dengan studi eksploratif, artinya penelitian ditujukan terhadap populasi tertentu yang dimaksudkan untuk mengeksplorasi bentuk suatu fenomena dengan jalan mendeskripsikan sejumlah variabel yang berkenaan dengan masalah yang diteliti. Fenomena yang dikaji adalah peristiwa rework dengan objek 32 proyek infrastruktur jalan di daerah Bali, NTB dan NTT.

Populasi penelitian adalah pihak owner proyek, responden digunakan hanya untuk mengeksplorasi peristiwa aktual terjadinya rework menggunakan teknik wawancara dengan variabel penyebab diperoleh dari hasil kuisioner yang interaksi hubungan antar variabelnya dideskripsikan dalam bentuk Kausatik Diagram. Pengembangan model menggunakan pendekatan sistem dinamik, yang mana model Kausatik Diagram nantinya direpresentasikan dalam bentuk Stock Flow Diagram (SFD). Nilai input variabel pada SFD diperoleh dari pengumpulan data sekunder, sedangkan bentuk hubungan antar variabel diinterprestasikan dalam bentuk formulasi matematika yang diperoleh menggunakan bantuan regresi linear berganda. Validasi model menggunakan perbandingan rata-rata dan perbandingan variasi amplitudo, yang keduanya membandingkan antara hasil simulasi dengan data historis menggunakan syarat validitas tertentu.

\section{Hasil dan Pembahasan}

Populasi penelitian adalah pihak owner yaitu para pejabat pembuat komitmen (PPK) di Direktorat Jenderal Bina Marga Balai Pelaksanaan Jalan Nasional yang membawahi pelaksanaan pembangungan infrastruktur jalan dan jembatan untuk wilayah Indonesia bagian Tengah dan Timur. Responden berjumlah 8 orang yang berpengalaman dalam menangani proyek infrastruktur jalan rata - rata $>15$ tahun dengan mayoritas bergelar S2, statistik deskriptif untuk profil responden disediakan pada tabel 1 dan tabel 2 .

Tabel 1. Profil Pendidikan Responden

\begin{tabular}{lcc}
\hline \multicolumn{1}{c}{ Deskripsi } & $\begin{array}{c}\text { Jumlah } \\
\text { Responden }\end{array}$ & $\begin{array}{c}\text { Persentase } \\
(\%)\end{array}$ \\
\hline Strata Pendidikan & & \\
1. S1 & 1 & 12,5 \\
2. S2 & 7 & 87,5 \\
3. S3 & 0 & 0 \\
\hline Total & 8 & 100 \\
\hline
\end{tabular}

Sumber: Hasil Analisis

Tabel 2. Profil Pengalaman Responden

\begin{tabular}{lcc}
\hline \multicolumn{1}{c}{ Deskripsi } & $\begin{array}{c}\text { Jumlah } \\
\text { Responden }\end{array}$ & $\begin{array}{c}\text { Persentase } \\
(\%)\end{array}$ \\
\hline Pengalaman & 0 & 0 \\
1. $<5$ tahun & 1 & 12,5 \\
2. $5-9$ tahun & 1 & 12,5 \\
3.10-15 tahun & 6 & 75 \\
4. $>15$ tahun & 8 & 100 \\
\hline Total & & \\
\hline
\end{tabular}

Sumber: Hasil Analisis

Owner dipilih sebagai populasi penelitian dikarenakan pihak owner lebih mengetahui detail peristiwa rework yang terjadi serta lebih terbuka dalam memberikan penjelasan mengenai detail peristiwa rework tersebut, jika dibandingkan dengan pihak kontraktor. Responden berjumlah 8 orang yang mana jumlah tersebut terbilang sedikit tetapi, respon yang diperoleh dapat dikatakan berkualitas dikarenakan mayoritas kompetensi dari para responden rata-rata memiliki pengalaman >18 tahun dalam menangani proyek infrastruktur jalan serta menyandang gelar master degree (S2) dalam bidang keilmuan teknik sipil.

Model peristiwa rework dideskripsikan ke dalam bentuk kausatik diagram yang dapat dilihat pada gambar 1 . Variabel penyebab dirumuskan dari beberapa studi literatur yang relevansinya diperoleh menggunakan bantuan kuisioner, sedangkan bentuk hubungan antar variabelnya dieksplorasi menggunakan teknik wawancara, tiap responden diajukan pertanyaan yang sama apakah pernah mengalami kejadian 
rework pada proyek yang pernah/sedang ditangani, jika pernah maka responden tersebut diminta untuk menceritakan detail kejadiannya, tiap cerita dirangkum dalam bentuk diagram kausatik yang divalidasi secara oral kepada responden yang bersangkutan, apakah bentuk model sudah sesuai mencerminkan kejadian aktualnya.

Hubungan antar variabel pada diagram kausatik dinyatakan dalam bentuk tanda panah, ekor dari anak panah menunjukkan causation (penyebab) sedangkan kepala dari anak panah menunjukan menunjukan effect (dampak) dari suatu penyebab. Jika variabel pada ekor anak panah berbanding lurus terhadap variabel pada kepala anak panah, maka anak panah yang menghubungkan variabel tersebut bernilai positif (+). Sedangkan jika variabel pada ekor anak panah berbanding terbalik terhadap variabel pada kepala anak panah, maka anak panah yang menghubungkan variabel tersebut bernilai negatif (-).

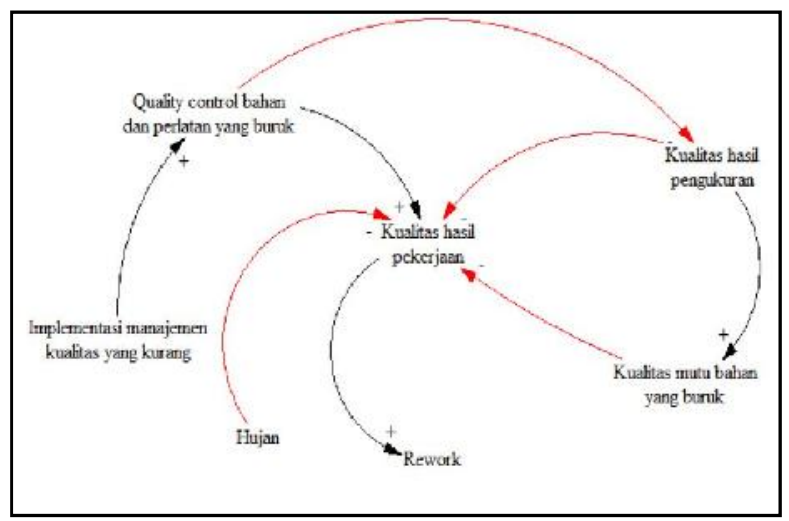

Gambar 1. Model Kausatik Diagram

(Sumber: Hasil Analisis)

Agar model mampu menggambarkan struktur aliran secara rinci dan matematis, maka model kausatik diagram perlu diubah ke bentuk model stock flow diagram (SFD).

Stock flow diagram menggambarkan hubungan antar variabel dan sudah dinyatakan dalam bentuk simbol - simbol, yaitu simbol yang menunjukan level atau stock, rate, auxiliary dan source atau sink. Level menyatakan kondisi sistem pada setiap saat, merupakan akumulasi yang terjadi di dalam sistem. Rate merupakan suatu struktur kebijaksanaan yang menjelaskan mengapa dan bagaimana suatu keputusan dibuat berdasarkan kepada informasi yang tersedia di dalam sistem, rate inilah satu-satunya variabel dalam model yang dapat mempengaruhi level. Auxiliary adalah beberapa hal yang dapat melengkapi variabel stock dan rate dalam memodelkan sistem dinamik, sedangkan source atau sink adalah rangkaian komponen-komponen diluar batas model.
Bentuk stock flow diagram kejadian rework dapat dilihat pada gambar 2.

Dari model SFD pada gambar 2 dapat dilihat bahwa model memiliki 3 auxiliary yang mempengaruhi rate penambahan jumlah rework, yang mana rate tersebut mempengaruhi laju penambahan level persentase jumlah rework. Auxiliary sendiri juga dipengaruhi oleh beberapa parameter, nilai tiap auxiliary diperoleh menggunakan persamaan perbandingan antara 2 parameter yang mempengaruhinya, dimana nilai untuk tiap parameter diperoleh dari hasil pengumpulan data sekunder pada 32 proyek jalan di daerah Bali, NTB dan NTT seperti laporan Marshall Test, daftar simak quality control dan laporan harian proyek. Nilai untuk tiap auxiliary dapat dilihat pada tabel 2.

Perumusan formulasi pada rate menggunakan metode regresi linear berganda, dimana ketiga auxiliary bertindak sebagai independent variables (variabel bebas) sedangkan level bertindak sebagai dependent variables (variabel terikat) yang diolah menggunakan program SPSS. Nilai input level diperoleh dari laporan hasil audit teknis jumlah kejadian rework dari 32 proyek sebelumnya. Dari hasil olahan diperoleh persamaan rate laju penambahan jumlah rework sebagai berikut:

$\mathrm{Y}=3,436-2,523\left(\mathrm{X}_{1}\right)+0,343\left(\mathrm{X}_{2}\right)-0,461\left(\mathrm{X}_{3}\right)$

dimana y adalah persentase jumlah rework, $\mathrm{X}_{1}$ adalah nilai mutu material, $\mathrm{X}_{2}$ adalah nilai kelengkapan quality control dan $\mathrm{X}_{3}$ adalah nilai perubahan cuaca.

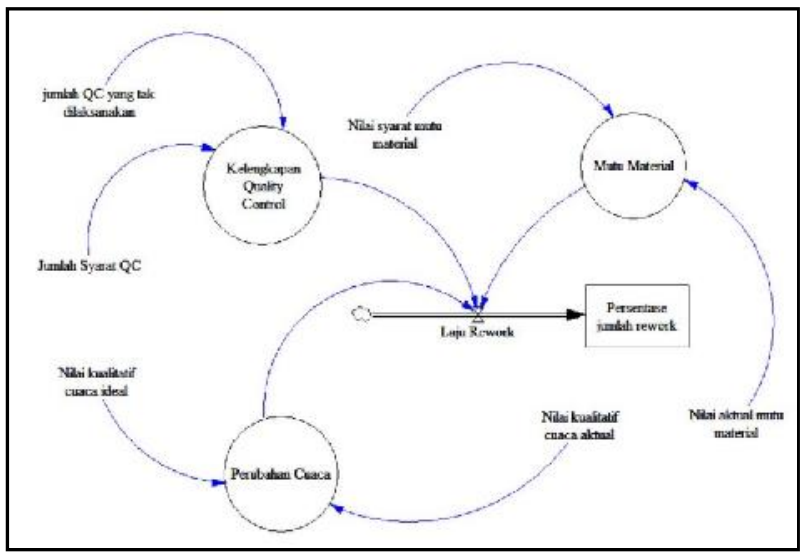

Gambar 2. Model Stock Flow Diagram

Untuk menentukan apakah model telah merepresentasikan sistem yang sebenarnya dengan tepat dan memenuhi tujuan dari pembuatan model secara keseluruhan maka perlu dilakukan validasi terhadap model tersebut [9]. Validasi 
model merupakan proses pengujian terhadap model apakah model yang dibuat sudah sesuai dengan sistem aktual.

Tabel 2. Nilai Auxiliary Model SFD Kejadian Rework

\begin{tabular}{cccc}
\hline Kode & \multicolumn{3}{c}{ Nilai Auxiliary } \\
lokasi & Mutu & Kelengkapan & $\begin{array}{c}\text { Perubahan } \\
\text { cuaca }\end{array}$ \\
\hline m.1 & 0,936 & 0,306 & 0,500 \\
L.2 & 0,994 & 0,167 & 1,000 \\
L.3 & 0,967 & 0,417 & 0,500 \\
L.4 & 0,997 & 0,306 & 0,750 \\
L.5 & 0,972 & 0,389 & 0,500 \\
L.6 & 0,999 & 0,000 & 1,000 \\
L.7 & 0,987 & 0,361 & 0,500 \\
L.8 & 0,989 & 0,361 & 0,500 \\
L.9 & 1,000 & 0,333 & 0,750 \\
L.10 & 0,987 & 0,444 & 0,500 \\
L.11 & 0,993 & 0,417 & 1,000 \\
L.12 & 0,991 & 0,444 & 1,000 \\
L.13 & 0,978 & 0,444 & 1,000 \\
L.14 & 0,987 & 0,472 & 0,750 \\
L.15 & 0,983 & 0,472 & 0,750 \\
L.17 & 0,990 & 0,250 & 1,000 \\
L.18 & 0,995 & 0,444 & 0,750 \\
L.19 & 0,983 & 0,472 & 0,500 \\
L.20 & 0,998 & 0,361 & 1,000 \\
L.21 & 0,944 & 0,500 & 0,250 \\
L.22 & 0,985 & 0,444 & 1,000 \\
L.23 & 0,938 & 0,444 & 0,250 \\
L.24 & 0,984 & 0,417 & 0,750 \\
L.25 & 0,992 & 0,306 & 1,000 \\
L.26 & 0,988 & 0,472 & 0,750 \\
L.27 & 0,965 & 0,389 & 0,500 \\
L.28 & 0,992 & 0,361 & 1,000 \\
L.29 & 0,994 & 0,361 & 1,000 \\
L.30 & 0,997 & 0,417 & 1,000 \\
L.31 & 0,986 & 0,361 & 1,000 \\
L.32 & 0,987 & 0,389 & 0,750 \\
\hline Sumber: & &
\end{tabular}

Sumber: Hasil Analisis

Menurut Barlas, validasi model secara kuantitaif pada sistem dinamik menggunakan Mean Comparison (perbandingan rata-rata) dan Amplitude Variation Comparison (perbandingan variasi amplitudo), dengan persamaan masingmasing sebagai berikut [10] :

$\mathrm{E} 1=\frac{|\mathrm{S}-\mathrm{A}|}{\mathrm{A}}$
$\mathrm{E} 2=\frac{|\mathrm{Ss}-\mathrm{Sa}|}{S a}$

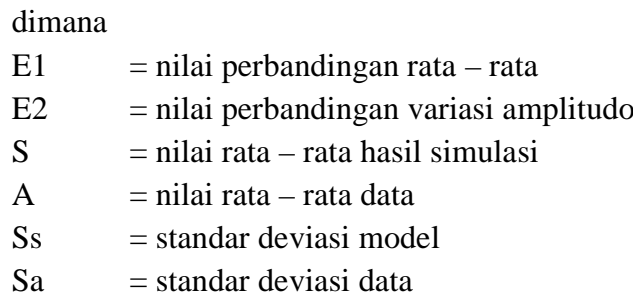

Model dikatakan valid jika nilai perbandingan rata - rata (E1) $\leq 5 \%$ dan nilai perbandingan variasi amplitudo (E2) $\leq$ $30 \%$. Dari gambar 3 dapat dilihat grafik persentase jumlah rework aktual untuk 32 proyek jalan di wilayah Bali, NTB dan NTT selama 2 tahun, dengan rincian 15 proyek di tahun 2013 dan 17 proyek di tahun 2014, sedangkan dari gambar 4 dapat dilihat grafik persentase jumlah rework hasil simulasi kontinyu menggunakan program VENSIM pada model SFD dengan time step per 1 bulan yang dibatasi selama 2 tahun sebagai data pembanding.

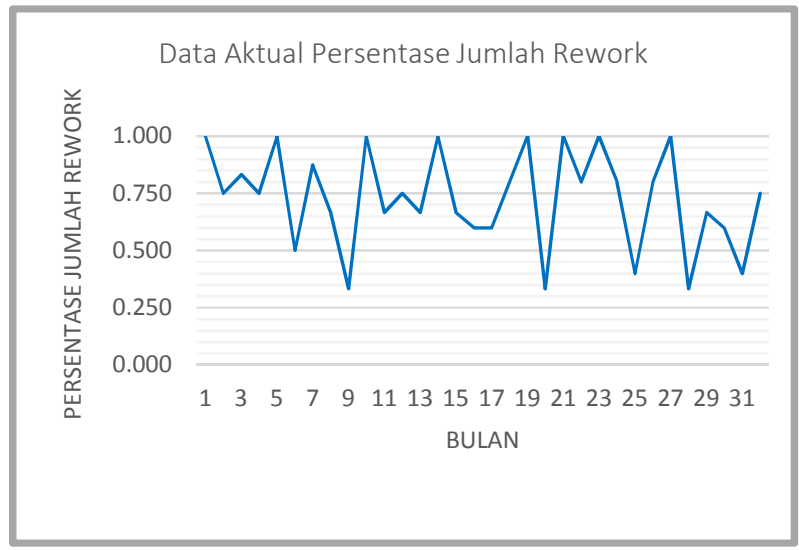

Gambar 3. Grafik Persentase Jumlah Rework Aktual di Tahun 2013 \& 2014

(Sumber: Hasil Analisis)

Berdasarkan hasil perbandingan data dari 2 grafik tersebut diperoleh nilai perbandingan rata-rata (E1) sebesar 2,87\% dan nilai perbandingan variasi amplitudo (E2) sebesar 24,07\%. Perbandingan data persentase jumlah kejadian rework aktual dan data hasil simulasi dapat dilihat pada tabel 3. Skenario perbaikan dilakukan menggunakan skenario parameter yaitu dengan jalan mengubah nilai parameter base model, skenario struktur dengan jalan mengubah struktur pada base model dan skenario kombinasi antara skenario struktur dan parameter yang keseluruhannya bertujuan mengurangi persentase jumlah rework pada proyek infrastruktur jalan. 


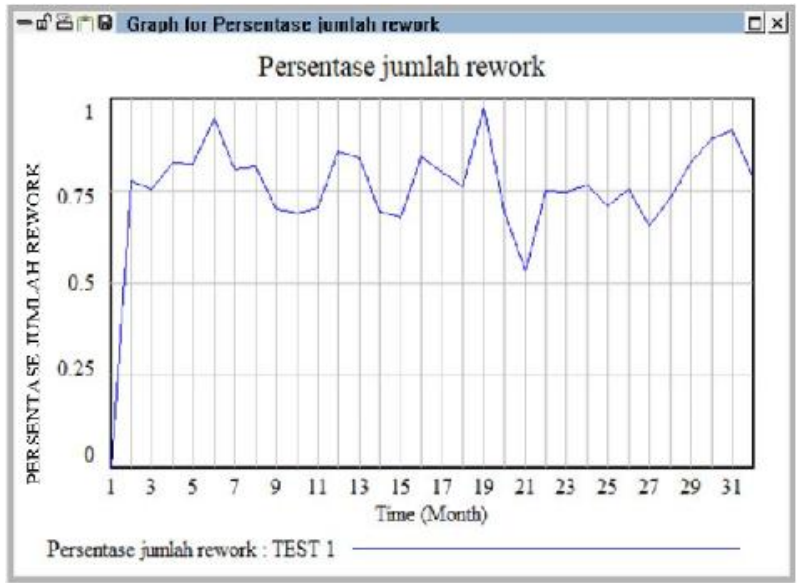

Gambar 4. Grafik Persentase Jumlah Rework Hasil Simulasi (Sumber: Hasil Analisis)

Tabel 3. Perbandingan Data Hasil Simulasi Dengan Data Aktual

\begin{tabular}{|c|c|c|}
\hline Bulan ke - & $\begin{array}{c}\text { Hasil simulasi base } \\
\text { model }(\%)\end{array}$ & $\begin{array}{l}\text { Data aktual } \\
\quad(\%)\end{array}$ \\
\hline 1 & 0 & 100 \\
\hline 2 & 77,726 & 75 \\
\hline 3 & 75,243 & 83 \\
\hline 4 & 82,726 & 75 \\
\hline 5 & 82,408 & 100 \\
\hline 6 & 94,361 & 50 \\
\hline 7 & 80,814 & 87 \\
\hline 8 & 81,641 & 66,7 \\
\hline 9 & 69,999 & 33,3 \\
\hline 10 & 68,793 & 100 \\
\hline 11 & 70,390 & 66,7 \\
\hline 12 & 85,514 & 75 \\
\hline 13 & 83,641 & 66,7 \\
\hline 14 & 69,096 & 100 \\
\hline 16 & 84,023 & 60 \\
\hline 17 & 79,837 & 60 \\
\hline 18 & 76,149 & 80 \\
\hline 19 & 97,323 & 100 \\
\hline 20 & 69,213 & 33,3 \\
\hline 22 & 74,998 & 80 \\
\hline 23 & 74,621 & 100 \\
\hline 24 & 76,452 & 80 \\
\hline 25 & 70,872 & 40 \\
\hline 26 & 75,206 & 80 \\
\hline 27 & 65,450 & 100 \\
\hline 28 & 73,015 & 33,3 \\
\hline 29 & 82,583 & 66,7 \\
\hline 30 & 88,976 & 60 \\
\hline 31 & 91,297 & 40 \\
\hline 32 & 77,977 & 75 \\
\hline
\end{tabular}

Sumber: Hasil Analisis
Tabel 4. Hasil Simulasi Skenario Perbaikan

\begin{tabular}{|c|c|c|c|}
\hline Skenario & $\begin{array}{c}\text { Jenis } \\
\text { skenario }\end{array}$ & $\begin{array}{c}\text { Kemampuan } \\
\text { meminimalisir } \\
\text { rework }(\%)\end{array}$ & Keterangan \\
\hline Skenario 1 & $\begin{array}{c}\text { Skenario } \\
\text { parameter }\end{array}$ & $11 \%$ & $\begin{array}{l}\text { Meningkatkan } \\
\text { nilai mutu } \\
\text { material hingga } \\
\text { sesuai dengan } \\
\text { persyaratan Bina } \\
\text { Marga yaitu } \\
\text { sebesar 98\% }\end{array}$ \\
\hline Skenario 2 & $\begin{array}{l}\text { Skenario } \\
\text { parameter }\end{array}$ & $20 \%$ & $\begin{array}{l}\text { Meningkatkan } \\
\text { nilai cuaca aktual } \\
\text { agar sesuai } \\
\text { dengan cuaca } \\
\text { ideal (cuaca } \\
\text { terik) }\end{array}$ \\
\hline Skenario 3 & $\begin{array}{l}\text { Skenario } \\
\text { parameter }\end{array}$ & $15 \%$ & $\begin{array}{l}\text { Mengurangi } \\
\text { jumlah quality } \\
\text { control yang tak } \\
\text { dilakukan hingga } \\
1 \text { item control } \\
\text { saja }\end{array}$ \\
\hline Skenario 4 & $\begin{array}{l}\text { Skenario } \\
\text { parameter }\end{array}$ & $39 \%$ & $\begin{array}{l}\text { Meningkatkan / } \\
\text { mengurangi nilai } \\
\text { mutu material, } \\
\text { nilai cuaca aktual } \\
\text { \& jumlah QC } \\
\text { yang tak } \\
\text { dilakukan hingga } \\
\text { nilai optimum }\end{array}$ \\
\hline Skenario 5 & $\begin{array}{c}\text { Skenario } \\
\text { struktur }\end{array}$ & $18 \%$ & $\begin{array}{l}\text { Menambah rate } \\
\text { laju pengurangan } \\
\text { rework yang } \\
\text { dipengaruhi } \\
\text { auxiliary } \\
\text { kecakapan dan } \\
\text { pengawasan } \\
\text { kerja }\end{array}$ \\
\hline Skenario 6 & $\begin{array}{c}\text { Skenario } \\
\text { struktur + } \\
\text { parameter }\end{array}$ & $26 \%$ & $\begin{array}{l}\text { Kombinasi } \\
\text { skenario } 1 \text { dan } \\
\text { skenario } 5\end{array}$ \\
\hline Skenario 7 & $\begin{array}{c}\text { Skenario } \\
\text { struktur }+ \\
\text { parameter }\end{array}$ & $34 \%$ & $\begin{array}{l}\text { Kombinasi } \\
\text { skenario } 2 \text { dan } \\
\text { skenario } 5\end{array}$ \\
\hline Skenario 8 & $\begin{array}{c}\text { Skenario } \\
\text { struktur + } \\
\text { parameter }\end{array}$ & $31 \%$ & $\begin{array}{l}\text { Kombinasi } \\
\text { skenario } 3 \text { dan } \\
\text { skenario } 5\end{array}$ \\
\hline Skenario 9 & $\begin{array}{l}\text { Skenario } \\
\text { struktur + } \\
\text { parameter }\end{array}$ & $51 \%$ & $\begin{array}{l}\text { Kombinasi } \\
\text { skenario 1, } \\
\text { skenario 2, } \\
\text { skenario } 3 \text { dan } \\
\text { skenario } 5\end{array}$ \\
\hline
\end{tabular}

Sumber: Hasil Analisis 
Skenario parameter dilakukan pada parameter pada base model yaitu parameter nilai mutu aktual material, nilai kualitatif cuaca aktual dan jumlah quality control yang tak dilakukan, sedangkan skenario struktur dilakukan dengan menambahkan struktur baru yaitu rate laju pengurangan rework dimana nilainya dipengaruhi oleh auxiliary pengawasan kerja dan kecakapan kerja dengan parameter-parameter yang mempengaruhinya yaitu tingkat pendidikan, peran aktif, pengalaman kerja, pengalaman pengawasan kerja dan tingkat keterlibatan seperti yang dapat dilihat pada gambar 5, dimana nilai tiap parameter diperoleh menggunakan teknik Matrik Pairwise Comparison dengan bantuan kuisioner yang diolah menggunakan program Analytical Hierarchy Process (AHP). Hasil simulasi tiap skenario beserta rumusan solusinya dapat dilihat pada tabel 4 .

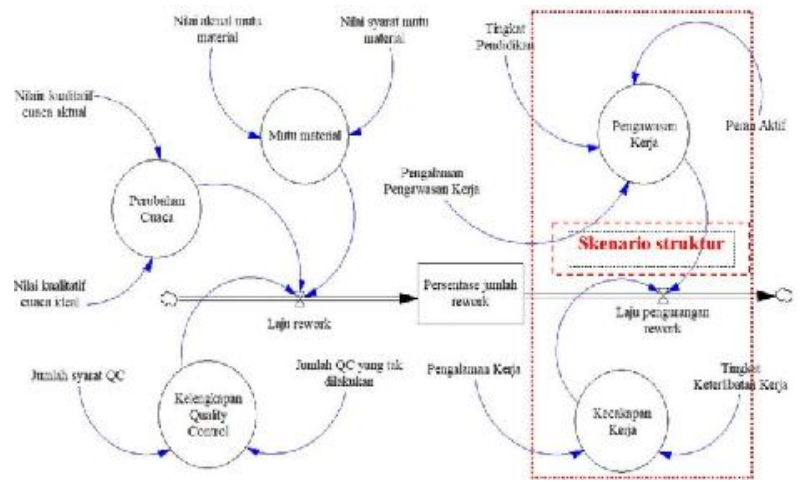

Gambar 5. Skenario struktur yang akan diterapkan pada base model

(Sumber: Hasil Analisis)

\section{Simpulan}

Pada tabel 4 dirangkum perumusan skenario perbaikan dan kemampuan tiap skenario tersebut dalam mengurangi persentase jumlah rework beserta bentuk implementasi aktual masing-masing, jika nanti suatu skenario dipilih untuk diterapkan. Perumusan skenario perbaikan terdiri dari 4 skenario parameter, 1 skenario struktur dan 4 skenario kombinasi antara skenario parameter dengan skenario struktur, masing-masing skenario memiliki kelebihan serta kekurangan dari segi kemampuan dan kemudahan implementasinya, pemilihan skenario dilakukan dengan memilih 3 skenario terbaik berdasarkan kemampuan tiap skenario dalam mengurangi persentase jumlah rework, kemudian dilanjutkan dengan menilai kemudahan implementasi dari 3 skenario tersebut. Skenario yang dipilih untuk dilterapkan adalah skenario yang memiliki kemampuan optimum dalam mengurangi persentase jumlah rework dengan bentuk implementasi termudah.
Berikut 3 skenario terpilih berdasarkan kemampuan skenario dalam mengurangi persentase jumlah rework jika dilaksanakan untuk 1 tahun kedepan, skenario tersebut adalah skenario 9, skenario 4, dan skenario 7. Skenario 9 merupakan skenario kombinasi antara skenario struktur dengan 3 skenario parameter yang mana merupakan skenario terlengkap dari skenario perbaikan lainnya, skenario 9 mampu mengurangi persentase jumlah rework dengan nilai yang paling signifikan yaitu sebesar $51 \%$, tetapi agar dapat mengurangi persentase jumlah rework hingga setengahnya, skenario 9 perlu menerapkan 7 bentuk implementasi yang merupakan implementasi gabungan dari 8 skenario lainnya. Skenario 4 juga merupakan skenario kombinasi yaitu kombinasi antara 3 skenario parameter tanpa diikuti skenario struktur, skenario ini mampu mengurangi persentase jumlah rework sebesar $34 \%$ jika menerapkan 5 bentuk implementasi, sedangkan untuk skenario 7 merupakan skenario kombinasi antara 1 skenario parameter dengan skenario struktur dengan jumlah implementasi paling sedikit dari 2 skenario sebelumnya dengan 3 bentuk implementasi, sekenario 7 mampu mengurangi persentase jumlah rework sebesar $34 \%$.

Berdasarkan pemaparan tersebut dapat diketahui bahwa skenario 9 adalah skenario yang paling mampu mengurangi persentase jumlah rework secara signifikan, tetapi dengan implementasi tersulit untuk dilaksanakan, dikatakan sulit karena selain jumlah implementasinya merupakan jumlah terbanyak jika dibandingkan dengan 2 skenario lainnya juga terdapat 2 bentuk implementasi yang tidak mudah untuk diwujudkan yaitu pengambilan material dari quarry di daerah lain dan melakukan kegiatan pengaspalan pada bulan Juni hingga Agustus. Dari hasil wawancara perumusan implementasi untuk mengambil material dari quarry di daerah lain disebabkan oleh material yang digunakan pada kebanyakan proyek infrastruktur jalan di daerah Bali, NTB dan NTT menggunakan material lokal dengan mutu yang kurang baik walaupun rata-rata nilai mutunta telah mendekati nilai mutu yang dipersyaratkan, tetap digunakannya material dengan mutu kritis tersebut dikarenakan desakan pemerintah daerah untuk tetap menggunakan material lokal dengan dasar bahwa nilai mutunya masih dapat diterima, kesulitan mewujudkan implementasi ini adalah meyakinkan pemerintah daerah agar tidak menggunakan material lokal dan menyetujui untuk mengambil material dari daerah lain yang tentunya akan memakan waktu dan biaya lebih jika dibandingkan menggunakan material lokal yang rata-rata berjarak lebih dekat ke site proyek, sedangkan implementasi untuk melakukan kegiatan pengaspalan pada bulan Juni hingga Agustus disebabkan oleh mutu hasil pengaspalan dapat menurun jika terkena air hujan, untuk meminimalisir 
resiko tersebut maka kegiatan pengaspalan sebaiknya dilakukan pada bulan Juni hingga Agustus untuk menghindari musim penghujan, kesulitan mewujudkan implementasi ini adalah sulitnya menjadwalkan kegiatan pengaspalan agar dilakukan pada bulan Juni hingga Agustus jika proyek dimulai lama sebelumnya atau malah setelah rentan bulan tersebut, selain itu juga tidak ada jaminan apakah pada rentan bulan tersebut tidak akan terjadi hujan, sehingga implementasi ini hanya berlaku jika diasumsikan tidak terjadi anomali cuaca. Skenario 4 menjadi skenario dengan implementasi tersulit kedua dengan 5 bentuk implementasi yang termasuk 2 implementasi yang dirasa sulit untuk diterapkan yang telah dibahas sebelumnya, sedangkan skenario 7 menjadi skenario yang termudah dengan 3 bentuk implementasi dengan hanya 1 implementasi sulit untuk diterapkan yaitu melakukan kegiatan pengaspalan pada bulan Juni hingga Agustus.

Berdasarkan pemaparan dapat disimpulkan bahwa skenario 7 adalah skenario terbaik karena mampu mengurangi persentase jumlah rework secara optimum dengan implementasi yang relatif mudah jika dibandingkan dengan skenario 9 dan skenario 4. Dari hasil simulasi, dengan menerapkan skenario 7 sebagai skenario perbaikan, skenario tersebut mampu mengurangi persentase jumlah rework pada proyek infrastruktur jalan sebesar 34\% untuk 1 tahun kedepan dengan melakukan 3 implementasi berikut secara simultan, yaitu dengan melakukan kegiatan pengaspalan hanya pada rentan bulan Juni hingga Agustus. Pemilihan rentan bulan tersebut agar meminimalisir resiko turunnya hujan, menurut Tjasyono dkk, musim kemarau di Indonesia terjadi terutama pada bulan Juni-juli-Agustus, hal ini dikarenakan terjadi penurunan jumlah curah hujan tahunan dan musiman pada rentan bulan tersebut akibat pengaruh El Nino/IOD(+) [11]. Menghindari resiko hujan dimaksudkan karena air hujan dapat mengurangi kualitas aspal yang telah dihampar, hal ini sejalan dengan hasil penelitian yang dilakukan oleh Arifin, menurut Arifin, secara keseluruhan nilai karakteristik Marshall mengalami penurunan seiring bertambahnya kandungan air hujan, hal ini mengindikasikan menurunnya kualitas dan kinerja campuran beraspal jika kegiatan pengaspalan dilakukan di saat hujan [12].

Implementasi kedua adalah dengan memberikan pelatihan serta seminar secara berkala dan berkesesuaian kepada para pekerja dan pengawas, hal ini juga didukung oleh beberapa hasil penelitian, menurut Ekaramban, salah satu cara yang mampu dalam mengurangi jumlah kejadian rework secara signifikan yaitu dengan meningkatkan kecakapan kerja malalui pembelajaran dan pelatihan, seperti penerapan lesson learned framework yang dikemas dalam bentuk seminar/diskusi ringan dengan muatan materi berupa berbagi cerita kesuksesan dan kegagalan dalam menangani suatu proyek konstruksi berdasarkan pengalaman dari narasumber berkompeten [13]. Sedangkan menurut Alwi dkk, dengan meningkatkan kompetensi pengawas melalui pelatihan secara layak dan berkala mampu mengurangi dampak yang diakibatkan oleh rework sebesar 11\%-22\% [14].

Implementasi ketiga yaitu dengan merekrut pekerja dan pengawas yang berpengalaman serta berpendidikan. Pentingnya pengalaman dan pendidikan tersebut sejalan dengan hasil penelitian yang dilakukan oleh Foster[14]. Faktor pendidikan, pelatihan, peran aktif dan pengalaman memberikan pengaruh yang signifikan $(75,05 \%)$ terhadap kompetensi seorang pengawas, sejalan dengan hal tersebut, Ravianto menjelaskan pendidikan membentuk dan menambah pengetahuan seseorang untuk mengerjakan sesuatu dengan lebih cepat dan tepat, sedangkan pelatihan membentuk dan meningkatkan kecakapan kerja, jika suatu pekerjaan yang dilaksanakan dengan tepat serta ditambah dilakukan oleh pekerja yang memiliki kecakapan kerja mumpuni niscaya kejadian rework tidak akan terjadi. Untuk tingkat pengalaman bagi seorang pekerja, Foster, menyatakan bahwa semakin berpengalaman seorang pekerja di suatu bidang memberikan pengaruh yang signifikan terhadap keterampilan kerjanya[14], [15].

\section{Daftar Pustaka}

[1] P. Barber, A. Graves, M. Hall, D. Sheath, and C. Tomkins, "Quality failure costs in civil engineering projects," Int. J. Qual. Reliab. Manag., vol. 17, no. 4/5, pp. 479-492, Jun. 2000.

[2] P. E. D. Love, Z. Irani, and D. J. Edwards, "A Rework Reduction Model for Construction Projects," IEEE Trans. Eng. Manag., vol. 51, no. 4, pp. 426-440, Nov. 2004.

[3] M. M. Kumaraswamy and D. W. M. Chan, "Contributors to construction delays," Constr. Manag. Econ., vol. 16, no. 1, pp. 17-29, Jan. 1998.

[4] J. Atkinson, The field rework index : early warning for field rework and cost growth. Austin Tex.: Construction Industry Institute, 2001.

[5] P. F. Kaming, P. O. Olomolaiye, G. D. Holt, and F. C. Harris, "Factors influencing craftsmen's productivity in Indonesia," Int. J. Proj. Manag., vol. 15, no. 1, pp. 21-30, Feb. 1997.

[6] E. Suryani, Pemodelan \&amp; Simulasi. Surabaya: Graha Ilmu, 2006.

[7] O. A. Aiyetan and D. Das, "Using System Dynamics 
Modelling Principles to Resolve Problem of Rework in Contruction Project in Nigeria," J. Constr. Proj. Manag. Innov., vol. 5, no. 2, pp. 1266-1295, Dec. 2015.

[8] N. Forcada, G. Rusiñol, M. MacArulla, and P. E. D. Love, "Rework in highway projects," J. Civ. Eng. Manag., vol. 20, no. 4, pp. 445-465, Jul. 2014.

[9] J. Harel, C. Koch, and P. Perona, "Graph-Based Visual Saliency," in Advances in neural information processing systems, 2007, pp. 545-552.

[10] Y. Barlas, "Formal aspects of model validity and validation in system dynamics," Sist. Dyn. Rev., vol. 12, no. 3, pp. 183-210, 1996.

[11] B. T. HK, A. L. Ruminta, I. Juaeni, and S. W. B. Harijono, "Dampak Variasi Temperatur Samudera Pasifik dan Hindia Ekuatorial Terhadap Curah Hujan di Indonesia," J. Sains Dirgant., vol. 5, no. 2, pp. 8395, Jun. 2008.

[12] M. Z. Arifin, L. Djakfar, and G. Martina, "Pengaruh Kandungan Air Hujan Terhadap Nilai Karakteristik Marshall Dan Indeks Kekuatan Sisa (IKS) Campuran Lapisan Aspal Beton (LASTON)," Rekayasa Sipil, vol. 2, no. 1, pp. 39-46, May 1925.

[13] E. Palaneeswaran, "Reducing rework to enhance project performance levels," in Proceedings of the One day Seminar on "Recent Developments in Project Management in Hong Kong," 2006, p. 5.1-5.10.

[14] J. Foster, "Education as Sustainability," Environ. Educ. Res., vol. 7, no. 2, 2001.

[15] J. Ravianto, Produktivitas dan Manajemen. Jakarta: Lembaga Sarana Informasi Usaha dan Produktivitas, 1985. 